\title{
Keeping Up With Work Email After Hours and Employee Wellbeing: Examining Relationships During and Prior to the COVID-19 Pandemic
}

\section{Archana Manapragada Tedone ${ }^{1}$ (D)}

Received: 2 May 2021 / Revised: 30 October 2021 / Accepted: 3 December 2021 / Published online: 22 January 2022

(c) The Author(s), under exclusive licence to Springer Nature Switzerland AG 2021

\begin{abstract}
The COVID-19 pandemic has forced many employees to work from home (WFH) and more heavily rely on technology to conduct work, calling for further empirical investigation into the effects of work-related technology and the WFH environment on employee wellbeing. This study investigates the relationship between work-related email (WRE) use during nonwork hours and emotional exhaustion in a sample of U.S. employees required to WFH during the pandemic, with results suggesting that psychological detachment and work-family conflict (WFC) play important roles in this relationship. Furthermore, telepressure (i.e., the preoccupation/urge to promptly respond to WRE) moderated the relationship between WRE use and psychological detachment, which offers insight into the psychological processes behind WRE use after hours. Direct and indirect effects between WRE use and emotional exhaustion were also compared to effects generated using data from an independent sample of pre-pandemic in-office employees to determine whether the pandemic context has amplified the observed relationships. Results show that all direct/indirect effects, except for the effect of WRE use after hours on psychological detachment, were stronger in those required to WFH. These findings shed light onto the similarities and differences between the current and pre-pandemic work landscapes and have important implications for lawmakers, organizational leaders, and employees.
\end{abstract}

Keywords Work-related email use $\cdot$ Emotional exhaustion $\cdot$ Psychological detachment · Work-family conflict · Telepressure · COVID-19

Archana Manapragada Tedone atedone@ubalt.edu

1 Division of Applied Behavioral Sciences, University of Baltimore, 1415 Maryland Ave., Room 400, Baltimore, MD 21201, USA 
The proliferation of smartphones, tablets, and other portable communication devices has made it easier for employees to work from anywhere at any time. Email, in particular, has revolutionized the workplace by facilitating expeditious communication of information, with its saliency even more evident during the coronavirus disease (COVID-19) pandemic. As many United States (U.S.) employees have now shifted to working from home (U.S. Bureau of Labor Statistics, 2020), workplace communication is occurring more often through email. For many individuals, this "new normal" is likely to persist for months into the future, with some organizations making the decision to permanently adopt a virtual work environment (Lerman \& Greene, 2020). In this context, the increased reliance on email communication calls for further exploration into its implications on employee health and wellbeing.

The aim of the present study is to investigate how work-related email use during nonwork hours relates to employees' experiences of emotional exhaustion in the COVID-19 pandemic context. Keeping up with work-related email outside of work hours may hamper opportunities to mentally detach from the workplace (i.e., psychological detachment), which can be associated with increased conflict between work and family/home domains (i.e., work-family conflict), and, in turn, emotional exhaustion. In addition, this study examines whether proposed effects are stronger for those high in telepressure (i.e., a psychological state characterized by a preoccupation and urge to respond to work-related messages; Barber \& Santuzzi, 2015). These relationships are investigated in a sample of U.S. administrative assistants who have been required to work from home (WFH) due to the COVID-19 pandemic. To investigate how these effects might differ outside of the pandemic context, several effects were also tested in an independent sample of administrative assistants working in a pre-pandemic office environment, data from which were collected prior to the events of the COVID-19 pandemic. Figure 1 illustrates the full conceptual model.

The present study makes several important contributions to the literature. First, one of the many consequences of the COVID-19 pandemic has been a major disruption to how and where work is done. In the U.S., many non-essential, in-office workers shifted to a completely virtual work environment, and organizations and employees relied on technology more than ever to get the job done. These drastic changes to our world of work warrant new empirical examination into how the WFH environment and our increased reliance on technology impact worker health. Indeed, many organizational leaders are now struggling with making decisions around their

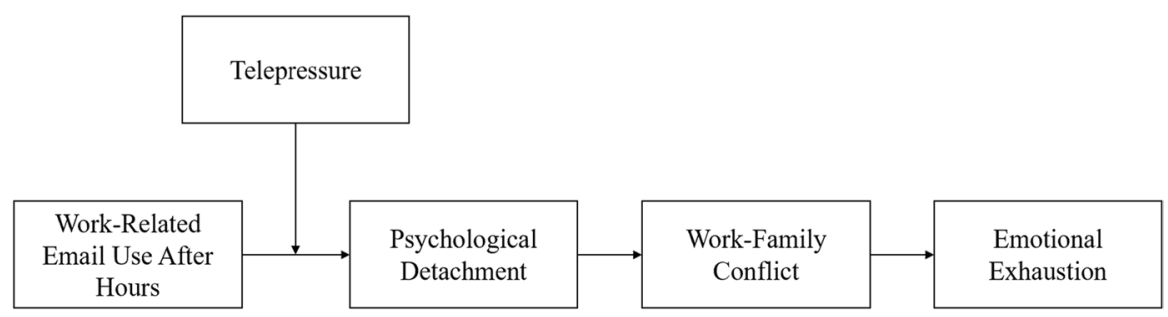

Fig. 1 Conceptual study model 
long-term remote work strategies (Makarius et al., 2021), however, relying upon research conducted prior to the COVID-19 pandemic to inform post-pandemic organizational policies and practices may not be appropriate, given the drastic differences in our current work landscape. The present study seeks to better understand the similarities and differences between the current and pre-pandemic work environment by investigating relationships between work-related technology, conflict between work and family/home domains, and worker wellbeing across both contexts. Although some of the relationships proposed in the present study have been established in pre-pandemic research (Barber \& Jenkins, 2014; Derks et al., 2014; Sonnentag \& Bayer, 2005), new investigation into whether these established effects still hold within the current WFH landscape is necessary for employees and organizational leaders to make informed decisions about how to best adapt to this "new normal."

Second, our reliance on email for daily work-related communication has increased exponentially due to the COVID-19 pandemic (PoliteMail, 2020). Prior to the pandemic, many large global organizations such as Volkswagen and Lidl were experimenting with restricting employees' use of work email outside of business hours. In addition, France passed a "right to disconnect" labor law in 2017 restricting the use of work-related email outside of typical work hours. Lawmakers in New York City have also had similar discussions, now stalled due to the COVID19 pandemic, around banning employers from requiring workers to keep up with work email during nonwork hours. Given the important organizational and legislative decisions that are being made around work-related email use, more empirical investigation into its relationship with worker wellbeing is warranted, as much of the research in this area has focused on information and communication technology (ICT) more generally (see Hu et al., 2021 for a review). Further, the implications of using email after hours likely differ in the current work environment, as work-home boundaries have become more permeable due to the COVID-19 pandemic. Indeed, the pandemic has resulted in a sharp increase in work email activity outside of work hours (PoliteMail, 2020), thereby decreasing the number of opportunities afforded to employees to mentally disconnect from the workplace. Further, prior to the pandemic, the physical boundary between the work and home environments may have acted as a stronger barrier between the two domains and could have buffered the spill over of work into nonwork domains via email. To that end, the present study aims to better understand how this increased reliance on work-related email relates to worker wellbeing by comparing relationships measured during and prior to the COVID-19 pandemic.

Third, research to date on ICT use and wellbeing has often overlooked the psychological processes underlying the behavior (Hu et al., 2021). In essence, it is not only important to establish that engaging in work-related technology after hours relates to negative wellbeing outcomes, but also to examine why or under what conditions these relationships exist. Accordingly, this research investigates the conditions under which keeping up with work-related email after hours relates to psychological detachment from work by examining whether individuals with varying levels of telepressure experience this relationship differently. For example, employees who have overwhelming feelings to promptly respond to messages as they are received 
(i.e., those high in telepressure) may experience fewer opportunities to mentally detach from the workplace due to an increase in nonwork time spent keeping up with and ruminating about work emails. Although research has begun to investigate the influence of telepressure on relationships between ICT use and psychological detachment (e.g., van Laethem et al., 2018), this study makes a novel contribution to the growing literature in this area by studying the implications of work-related email, in particular, and examining relationships in those working during COVID-19 pandemic. Telepressure is an especially important factor to consider for those required to WFH, as the work/home boundary is more permeable in such a work environment and work email may act as a vehicle through which work-related thoughts and tasks penetrate this boundary. Further, understanding the conditions under which workrelated email has negative implications for employees is crucial information to consider for organizations and lawmakers intending to pass "one-size-fits-all" policies and laws around its use.

\section{Work-Related Email Use During Nonwork Hours}

From its inception in the 1970s, the use of email for business purposes has been on a consistent rise (The Radicati Group, 2019), with the average U.S. full-time worker estimated to receive 120 emails per day (Plummer, 2019). These numbers have been exacerbated by the COVID-19 pandemic, with many face-to-face conversations now being replaced by email communications. Indeed, an analysis of over 650 million work emails by PoliteMail (2020) revealed a 95\% increase in work emails from February to March 2020, the period in which many organizations began requiring employees to WFH due to the pandemic. In addition, work emails being sent on the weekend increased by an alarming rate of $1121 \%$ during this same period, and still maintained an increase of around $200 \%$ by May 2020. These statistics suggest that the COVID-19 pandemic has led to an increased reliance on email, with more emails being sent during both work and nonwork hours.

Research supports the notion that the transportability and convenience of work email blurs the line between employees' work and nonwork domains (Boswell \& Olson-Buchanan, 2007; Clark, 2002; Golden, 2013; Towers et al., 2006). In support, results of the 2019 Adobe Email Usage Study suggest that the majority of Americans check their work email while "off the clock," with only $24 \%$ reporting that they do not check work email outside of normal working hours. Accessing email on mobile devices has also become the norm, with many workers $(50 \%)$ reporting that they check work emails on their smartphones (Fluent, 2018). Although the use of work email outside of work hours was on a steady rise, the COVID-19 pandemic led to a spike in email activity outside of work hours, warranting further empirical investigation into its relationship with employee wellbeing.

Work-related email (WRE) use during nonwork hours can be described as sending, reading, or checking emails relating to one's job outside of work hours. WRE can be considered a domain boundary spanning communication, as work email can be checked and sent while physically engaging in another domain (e.g., home, personal, family). According to boundary theory, although the integration of work and 
family domains may allow for easier transitions from one role to another, it can also increase the blurring of work and family roles, making it more challenging to create and maintain boundaries between the two domains (Ashforth et al., 2000). Therefore, WRE may facilitate a "spill over" of work into nonwork domains if employees are keeping up with WRE during nonwork hours, drastically reducing the number of opportunities to mentally disconnect from the workplace. In addition, if employees use mobile devices to check their WRE, they may develop an "always on" mentality in which they feel that they must be accessible at all times, further reducing the number of opportunities to disengage from the workplace. Indeed, WRE use during nonwork hours has been found to have a negative relationship with psychological detachment (Park et al., 2011), defined as a state in which one mentally disconnects from the job and job-related tasks while away from work (Sonnentag, 2012). In line with previous findings, it is hypothesized that those who constantly keep up with their WRE during nonwork hours are not able to fully psychologically detach from their work, given that engaging in WRE use during nonwork hours can produce a spill over of work-related tasks and thoughts into the family/home domain, thereby reducing the likelihood of sustained psychological detachment.

Hypothesis $1(H 1)$ : WRE use during nonwork hours is negatively related to psychological detachment.

\section{The Role of Psychological Detachment}

According to the stressor-detachment model, psychological detachment can be conceptualized as a mechanism through which job stressors produce strain outcomes (Sonnentag \& Fritz, 2015; Sonnentag et al. 2010). The model posits that elevated job stressors can hinder one's ability to mentally detach from work during nonwork time, which can result in strain and impaired wellbeing. Therefore, when one experiences increased stressors at work, mentally disconnecting and physically separating oneself from work can offer protection against further depletion of resources, such as time and energy (Sonnentag et al. 2010), by allowing employees to recharge and recover from the demands of the workday (Sonnentag et al., 2008). Furthermore, a recovery period is critical in preventing adverse wellbeing outcomes, such as fatigue and negative health symptoms (Sonnentag \& Bayer, 2005; Sonnentag \& Fritz, 2015; Sonnentag et al., 2010).

In addition to wellbeing, an important strain outcome to consider within the stressor-detachment framework is work-family conflict (WFC), which occurs when work demands interfere with family/home responsibilities (Netemeyer et al., 1996). Job stressors may prevent one from psychologically detaching from work during family time, which can then result in conflict between work and family/home domains. Indeed, psychological detachment has been identified as an important predictor of WFC (Demsky et al., 2014; Molino et al., 2015; Moreno-Jiménez et al. 2009). 
Hypothesis 2 (H2): Psychological detachment is negatively related to WFC.

Research also suggests that psychological detachment plays an important mediating role in the relationship between job stressors and work-family outcomes (e.g., workload, Germeys \& De Gieter, 2017; extended work availability, Dettmers, 2017; workplace aggression, Demsky et al., 2014). The indirect effect of job stressors on WFC through psychological detachment is likely to be exacerbated when job stressors can more easily penetrate the boundary between work and home (see work-home boundary theory; Ashforth et al., 2000). One such stressor that easily permeates the work-home boundary is WRE. Keeping up with WRE during nonwork hours can act as a stressor by 1) resulting in an increase in supplemental work, since WRE is being checked outside of work hours, 2) requiring individuals to repeatedly transition between work and family roles/tasks, and 3) serving as a vehicle through which additional job stressors can spill over into the family/home domain. In addition, the act of checking or sending WRE outside of work hours not only takes time away from family obligations, but can also affect one's psychological presence (i.e., attention-giving) during family time, especially when the content of the email leads to prolonged rumination about work (Minnen et al., 2020). Therefore, when employees keep up with their WRE during nonwork hours, they may be less likely to psychologically detach from their work, in turn eliciting conflict between work and home domains.

Hypothesis 3 (H3): WRE use during nonwork hours is indirectly related to WFC via psychological detachment.

An important wellbeing outcome to consider within the stressor-detachment framework is emotional exhaustion, a core component of employee burnout. Emotional exhaustion is defined as a chronic state of mental depletion resulting from prolonged exposure to stressors and/or excessive demands. Individuals who feel emotionally exhausted feel fatigued, mentally drained, and overwhelmed, and often feel that they are unable to recover from this state (Maslach et al., 2001). Research suggests that WFC is a critical antecedent of burnout (see Allen et al., 2000). When employees' work demands interfere with family/home responsibilities, resulting in conflict between the two domains, they may be more prone to experience a chronic depletion of mental energy.

Hypothesis 4 (H4): WFC is positively related to emotional exhaustion.

Given that emotional exhaustion can result from prolonged, inadequate recovery of resources expended at work (van Veldhoven, 2008), engaging in sustained WRE use during nonwork hours is likely to have an indirect relationship with emotional exhaustion through the mechanisms of psychological detachment and WFC. Psychological detachment has consistently been found to have a negative relationship with emotional exhaustion/burnout (Etzion et al., 1998; Sonnentag \& Fritz, 2007; Sonnentag et al., 2010), with some studies supporting a mediating effect of WFC (Dettmers, 2017; Medrano \& Trógolo, 2018). In addition, Dettmers (2017) 
found that extended work availability (i.e., being accessible and responsive to work demands during nonwork hours) impacts emotional exhaustion through psychological detachment and WFC. WRE use during nonwork hours can be considered a type of extended work availability, as checking and responding to WRE may signal to employers, subordinates, clients, or customers that one is available during nonwork hours. Building upon this prior research, it is proposed keeping up with WRE outside of work hours is associated with reduced opportunities for psychological detachment, increased conflict between work and family, and subsequently, emotional exhaustion.

Hypothesis 5 (H5): WRE use during nonwork hours is indirectly related to emotional exhaustion via psychological detachment and WFC.

\section{The Role of Telepressure}

Fluent's, 2018 Inbox survey reports that the majority of Americans (54\%) tend to check WRE in real-time upon receipt or at least several times a day. These statistics may indicate that some people feel a greater sense of pressure to respond to work-related messages as they are received. This phenomenon, termed telepressure, can be characterized as an internal psychological state in which one feels a preoccupation with and urge to respond to work-related messages quickly (Barber \& Santuzzi, 2015). Telepressure can result from both internal dispositions and tendencies (Barber \& Santuzzi, 2015), as well as external influences and demands from work (Kao et al., 2020). Although external expectations from the work environment (e.g., pressure from supervisors) may contribute to one's telepressure, it is important to note that not all workers internalize these expectations equally (Santuzzi \& Barber, 2018). Those who experience high levels of telepressure may be more likely to sacrifice their recovery periods to check or respond to WRE during nonwork time, which can then reduce opportunities for sustained psychological detachment.

One method through which telepressure can deter the recovery experience is by requiring individuals to continuously switch between work and family tasks if WRE is being checked during family time. Switching between work and family tasks could have a heavy cognitive burden; research in cognitive psychology suggests that continuously switching back and forth from tasks results in additional cognitive resources being spent on reorienting oneself with the task at hand (see American Psychological Association, 2006). In addition, although the act of checking WRE during nonwork hours may take up just a few minutes of nonwork time, its effects may persist long after an individual has finished reading or sending the email. For example, checking WRE may lead to work-related rumination, which can result in prolonged thoughts about work during nonwork time (Minnen et al., 2020). Furthermore, WRE can act as a bridge through which work demands and stressors can enter nonwork domains, as the content of an email may remind an individual of stressors experienced during the workday or upcoming work demands. Therefore, employees who have trouble concentrating on other activities or have overwhelming feelings to promptly respond upon receipt 
of work-related messages are more likely to keep up with WRE during nonwork time, and in turn may have fewer opportunities to mentally disconnect from the workplace due to not only the time commitment of checking WRE, but also the work-related rumination that may result.

Hypothesis 6 (H6): Telepressure moderates the relationship between WRE use during nonwork hours and psychological detachment, such that higher telepressure strengthens the relationship.

\section{Exploring Implications of the COVID-19 Pandemic}

The final aim of this study is to examine how the proposed relationships might differ across the COVID-19 pandemic and pre-pandemic contexts. To meet this aim, the proposed base model (i.e., the indirect effect of WRE use during nonwork hours on emotional exhaustion) will be tested using data collected from the same population pool of administrative assistants prior to the COVID-19 pandemic. It is proposed that path coefficients for the base model (WRE use during nonwork hours $\rightarrow$ psychological detachment $\rightarrow$ WFC $\rightarrow$ emotional exhaustion) will be stronger when generated using data collected from workers required to WFH during the COVID19 pandemic compared to those generated using data collected from in-office workers prior to the pandemic. More specifically, it is speculated that working from home blurs the physical boundary between the work and family/home domains and increases the reliance on WRE during both work and nonwork time. Keeping up with work email outside of work hours can facilitate the spill over of work into nonwork time and can in turn decrease the likelihood of sustained psychological detachment from work. Therefore, employees working from home are likely to experience greater negative wellbeing consequences due to WRE use during nonwork hours compared to workers with physically separate work and home environments.

Hypothesis 7 (H7): The proposed effects in H1-H6 are intensified in the WFH sample compared to the in-office pre-pandemic sample.

\section{Method}

This section outlines two data collection efforts: one for the primary study ( $\mathrm{H} 1$ H6) using a sample of workers required to WFH and the second for a comparison study (H7) using a sample of pre-pandemic in-office workers. Data for the primary study were collected from a sample of administrative assistants who shifted to working from home during the COVID-19 pandemic. Data for the comparison study were collected from a sample of administrative assistants working in an office environment prior to the COVID-19 pandemic. 


\section{Participants}

Participants in the primary study were 173 full-time U.S. administrative assistants who shifted to working from home due to the COVID-19 pandemic. The majority identified as female $(76 \%)$ and White $(50 \%)$, with ages ranging from 22 to 75 years $(M=45.31, S D=12.84)$. Participants reported working an average of $43.42 \mathrm{~h}$ per week $(S D=7.84)$, with an average job tenure of 7.52 years $(S D=7.93)$ and organizational tenure of 10.75 years $(S D=9.54)$. The majority of participants were married $(38 \%)$ or single $(23 \%)$ without children $(62 \%)$ and reported earning between $\$ 30 \mathrm{~K}$ to $\$ 60 \mathrm{~K}$ yearly $(58 \%)$.

The in-office worker sample consisted of 131 full-time U.S. administrative assistants. The majority of employees were female (86\%), with an average age of 35.14 ( $\mathrm{SD}=10.08)$. Most participants reported being married $(40 \%)$ or single $(31 \%)$ without children (54\%). Participants worked an average of $39.78 \mathrm{~h}$ per week $(\mathrm{SD}=4.97)$, and most reported earning a salary between $\$ 30 \mathrm{~K}$ to $\$ 50 \mathrm{~K}$ per year $(63 \%)$. Employees reported an average organizational tenure of 6.28 years $(\mathrm{SD}=4.98)$ and job tenure of 3.32 years $(\mathrm{SD}=3.32)$.

Given the differences in demographic characteristics of the two samples studied, a series of independent samples t-tests were conducted to identify whether differences across age, gender, hours worked per week, marital status, salary, organizational tenure, and job tenure are statistically significant. Gender $(t(268)=0.15, p=0.88)$ and marital status $(t(269)=0.12, p=0.90)$ were not found to statistically differ across samples. However, the WFH and in-office samples were found to significantly differ across age $(t(293)=7.30, p<0.05)$, hours worked per week $(t(346)=4.39, p<0.05)$, salary $(t(320)=4.57, p<0.05)$, organizational tenure $(t(231)=3.29, p<0.05)$, and job tenure $(t(269)=5.50, p<0.05)$.

\section{Procedure}

Potential participants in both data collection efforts were identified through public employee databases of college and university employees in the Southeastern U.S. Full-time employees working in administrative positions (e.g., administrative assistant, office assistant) were recruited for participation. Participants in the WFH sample were also required to have shifted to working from home due to the COVID-19 pandemic. All potential participants were emailed a description of the study, and those interested in participating were offered to complete an online survey including the measures in the following section. Participants were also encouraged to pass along the study information to coworkers who met the inclusion criteria. For the in-office worker sample, a total of 1771 potential participants were recruited, with 213 surveys returned (12\%). For the WFH sample, a total of 894 potential participants were recruited, with 196 surveys returned (22\%). All participants were compensated with a \$5 e-gift card upon successful completion of the survey. 


\section{Measures}

Work-Related Email Use During Nonwork Hours. In both samples, WRE use during nonwork hours was measured using a four-item measure by Manapragada (2017; WFH: $\alpha=0.95$; in-office: $\alpha=0.97$ ). Participants indicated the extent to which they agreed with statements such as "I tend to check my work-related emails after work hours" on a five-point Likert scale, with higher scores indicating greater WRE use after work hours.

Telepressure A six-item measure developed by Barber and Santuzzi $(2015 ; \alpha=0.90)$ was used to measure telepressure in the WFH sample. ${ }^{1}$ Items were modified to specifically reflect sending and receiving WRE. Items such as "It's hard for me to focus on other things when I receive a work-related email message" measured one's preoccupation with and urge to respond to work emails. Participants responded on a fivepoint Likert scale, with higher scores indicating more telepressure.

Psychological Detachment In both data collection efforts, a four-item measure (Sonnentag \& Fritz, 2007; WFH: $\alpha=0.87$; in-office: $\alpha=0.88$ ) was used to assess psychological detachment. Participants were asked to indicate the degree to which they can "...forget about work" and "...get a break from the demands of work" after work hours. Participants responded on a five-point Likert scale, with higher scores indicating more psychological detachment from work during nonwork hours.

Work-Family Conflict WFC was assessed using a five-item measure (Netemeyer et al., 1996) in the WFH sample ( $\alpha=0.95)$. An example item is "The demands of my work interfere with my home and family life." Participants responded on a five-point Likert scale, with higher scores indicating more WFC.

In the in-office worker sample, WFC was assessed using a two-item measure by Frone et al. (1992; $\alpha=0.89)$. An example item includes "How often does your job or career interfere with your responsibilities at home?" Participants responded on a five-point frequency scale, with higher scores indicating more WFC.

Emotional Exhaustion Emotional exhaustion was measured using a five-item subscale of the Maslach Burnout Inventory-General Survey (Schaufeli et al., 1996; WFH: $\alpha=0.89$; in-office: $\alpha=0.90$ ). An example item is "I feel emotionally drained from my work." Those in the WFH sample responded on a five-point Likert scale and in-office workers responded on a seven-point Likert scale, with higher scores indicating greater emotional exhaustion.

\footnotetext{
1 Telepressure was not included in the in-office data collection effort, as the original intent was to test only the proposed base model when data were collected in 2016. However, telepressure was added to the data collection effort in 2020 as the model was further developed in light of the pandemic work environment.
} 


\section{Factor Analysis}

To assess the factor structures of the study variables, a confirmatory factor analysis was conducted using data from the WFH sample. A measurement model in which WRE use, psychological detachment, telepressure, WFC, and emotional exhaustion were modeled as five separate latent factors with a total of 24 observed indicators was tested in IBM AMOS v28. This model had acceptable fit $(C M I N / D F=1.88, C F I=0.93, T L I=0.92, R M S E A=0.07, P C L O S E<0.05$, $A I C=617.85)$. Standardized factor loadings ranged from 0.67 to 0.96 . The fit dramatically improved after covarying the error terms for the items "I keep up with work emails after work hours" and "I check work-related emails after work hours" within the WRE use after hours measure $(C M I N / D F=1.60, C F I=0.95$, $T L I=0.94, R M S E A=0.06, P C L O S E=0.09, A I C=550.97)$. This modification may be justified by the high degree of overlap in the interpretation of these two items.

\section{Data Cleaning Procedures}

In the WFH sample, a total of 213 surveys were returned. Of those, 185 respondents met the inclusion criteria for participation. To address inattentive responding, five attention check questions (e.g., "Please select slightly disagree") were inserted at random points throughout the survey. Participants who did not respond appropriately to at least four $(80 \%)$ of these items were removed from further analyses (Behrend et al., 2011). This data cleaning procedure resulted in a final sample size of 173. Of those, 17 participants were missing responses to one or more survey items. Missing data were addressed with a multiple imputation technique using a regression method. Five datasets were imputed, and missing values were replaced with averaged scores across imputed datasets using the Bar Procedure (Baranzini, 2018). The resulting pooled dataset was used for all subsequent analyses.

The same data cleaning and imputation procedures were used for data from the sample of in-office workers collected prior to the COVID-19 pandemic. In this sample, a total of 140 eligible surveys were returned, with nine participants removed during the data cleaning process. Of the remaining 131 participants, seven were missing responses to one or more survey items. Missing values were replaced with average scores across five imputed datasets.

\section{Results}

Means, standard deviations, and intercorrelations among all primary study variables are shown in Table 1. Psychological detachment showed significant, negative relationships with WRE use during nonwork hours and WFC, supporting $H 1$ and $H 2$. WFC had a significant positive relationship with emotional exhaustion, supporting H4. 
Table 1 Descriptive statistics and intercorrelations among primary study variables for workers required to work from home during the COVID-19 pandemic

\begin{tabular}{lllllllll}
\hline & $M$ & $S D$ & 1 & 2 & 3 & 4 & 5 \\
\hline 1 & Work-Related Email Use After Hours & 3.60 & 1.17 & $(.95)$ & & & & \\
2 & Telepressure & 3.38 & 0.88 & .06 & $(.90)$ & & & \\
3 & Psychological Detachment & 3.16 & 0.87 & $-.55^{*}$ & $-.23^{*}$ & $(.87)$ & & \\
4 & Work-Family Conflict & 2.23 & 1.02 & $.22^{*}$ & $.26^{*}$ & $-.46^{*}$ & $(.95)$ & \\
5 & Emotional Exhaustion & 2.60 & 1.01 & $.17 *$ & $.20^{*}$ & $-.34^{*}$ & $.70^{*}$ & $(.89)$ \\
\hline
\end{tabular}

Note. ${ }^{*} \mathrm{p}<.05 ;$ Cronbach's alpha presented along diagonal

The full conceptual model (Fig. 1) was tested using a path analysis, in which all variables were modeled as observed constructs, in IBM AMOS v28. All variables were mean centered at 0 . The path model was found to have good fit with the data $(C M I N / D F=1.30, C F I=0.99, T L I=0.98, S R M R=0.05, R M S E A=0.04$, $P C L O S E=0.51$ ), and model fit statistics were superior to those of four alternative models, the results of which are summarized in Table 2. Estimates for all direct paths were significant at $p<0.05$ (see Fig. 2). A bias-corrected bootstrap procedure, with 2000 replicates, was used for testing indirect effects. The indirect effect between WRE use and WFC via psychological detachment was significant (unstandardized estimate $=0.20$, standardized estimate $=0.23$; CI $[0.15,0.32], \mathrm{p}<0.01)$, supporting $H 3$. The indirect effect of WRE use on emotional exhaustion through psychological detachment and WFC was also significant (unstandardized estimate $=0.14$, standardized estimate $=0.16$, CI [0.10, 0.23], $p<0.01$ ), supporting $H 5$.

Furthermore, the path coefficient for the interaction term was significant ( $b=-0.25, p<0.001)$, suggesting that telepressure moderates the relationship between WRE use and psychological detachment. Conditional effects were generated at \pm 1 SD from the mean of the moderator using the PROCESS macro for SPSS (Hayes, 2013), with results showing a greater effect of WRE use on psychological detachment at higher levels of telepressure $(b=-0.59, p<0.001)$ than lower levels of telepressure $(b=-0.15, p=0.02$; see Fig. 3$)$. H6 was supported.

[To test $H 7$, model fit was first assessed across the WFH sample and the prepandemic in-office sample. The base model was first fit to data collected from the WFH sample. The model showed good fit $(C M I N / D F=0.16, C F I=1.00, T L I=1.00$, $S R M R=0.01$, RMSEA $=0.00, P C L O S E=0.96$, $A I C=22.48$ ), and model fit statistics were superior to those of two alternative models (see Table 2). The same model was subsequently fit to data from the in-office sample (see Table 3 for means, SDs, and intercorrelations among variables from the in-office sample), which also showed good fit $(C M I N / D F=1.51, C F I=0.99, T L I=0.97, S R M R=0.05, R M S E A=0.06$, $P C L O S E=0.34, A I C=26.52$ ), with the model fit statistics superior to those of two alternative models (see Table 2). A chi-squared difference test was conducted to compare the fit of the WFH and in-office models using multigroup analysis in IBM AMOS, with results suggesting that there is a statistically significant difference in fit across both samples $\left(\chi^{2}=7.82, p<0.05\right)$. Although all proposed direct and indirect paths were statistically significant across both models (Table 4), the standardized coefficients for all 


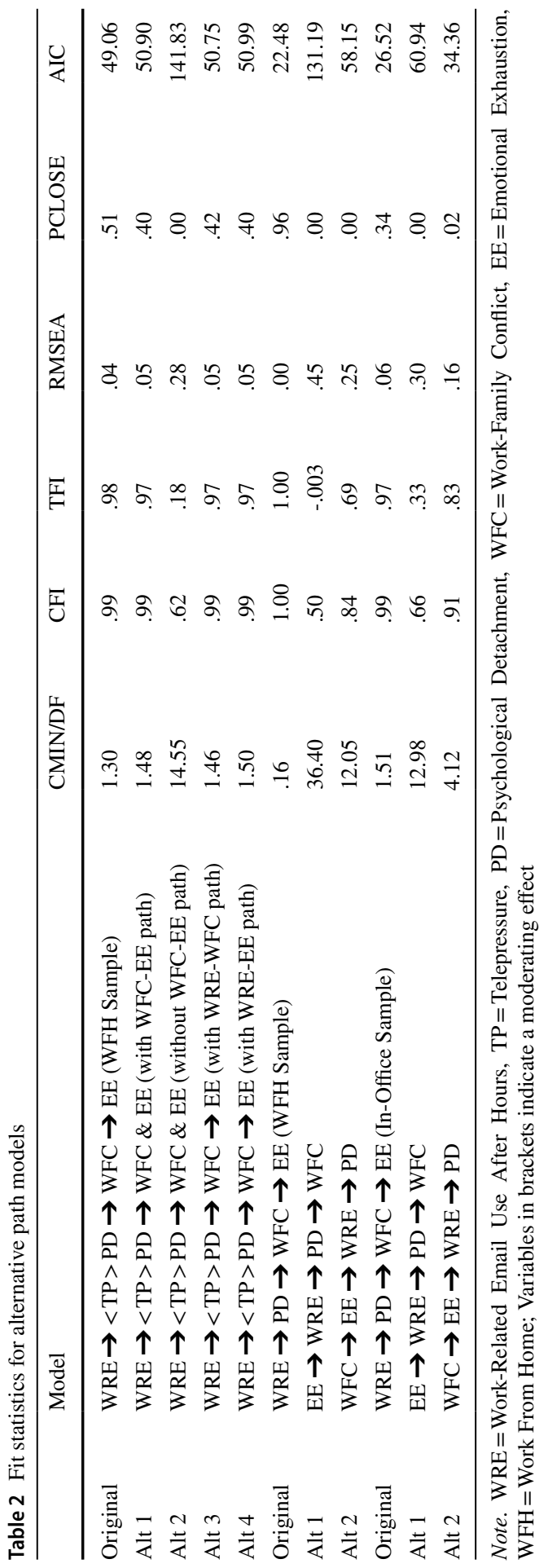




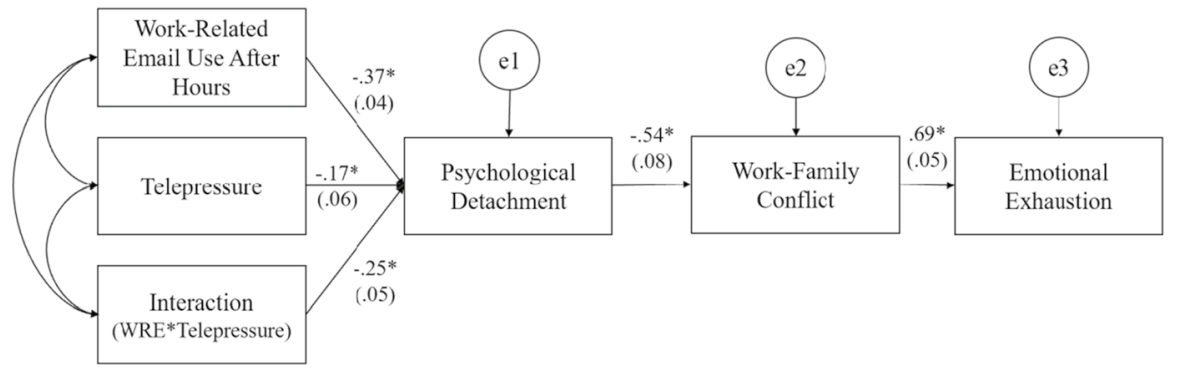

Note. ${ }^{*} \mathrm{p}<.05$; standard error shown in parentheses.

Fig. 2 Unstandardized path coefficients for all direct paths in the sample of workers required to work from home during the COVID-19 pandemic

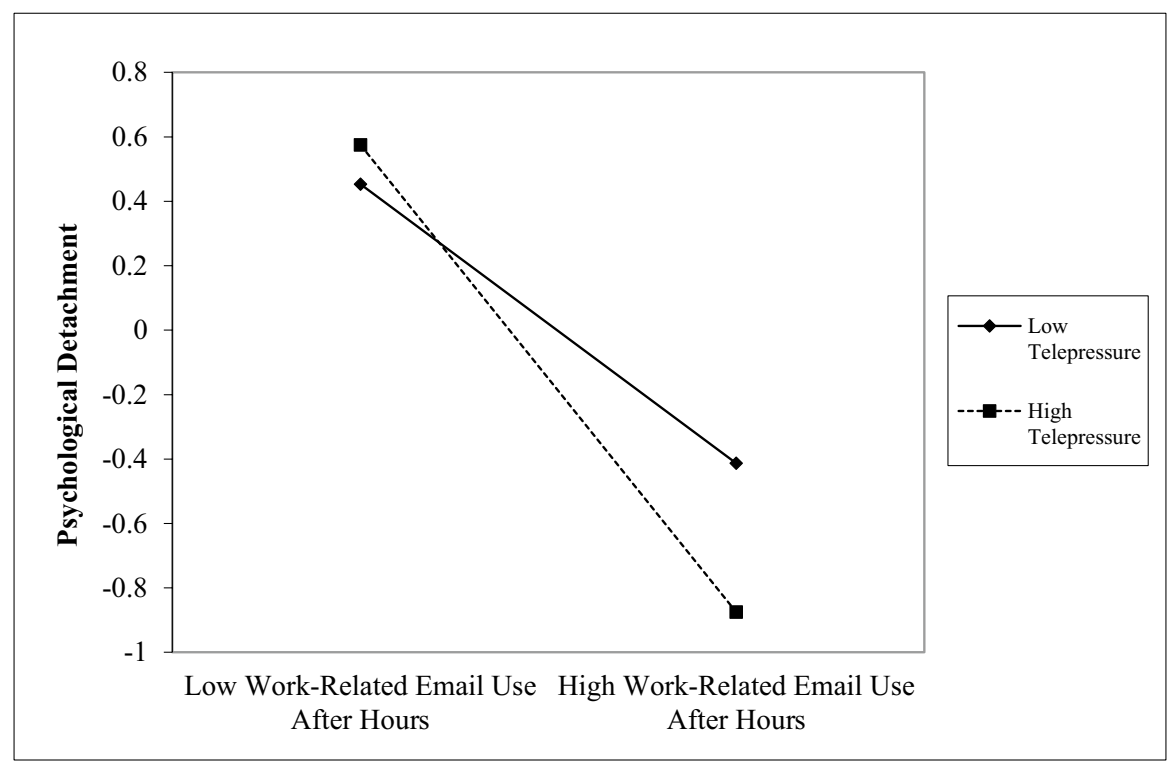

Fig. 3 The relationship between work-related email use after hours and psychological detachment at high (+1SD) and low (-1SD) levels of telepressure in workers required to work from home during the COVID-19 pandemic

Table 3 Descriptive statistics and intercorrelations among study variables for in-office workers collected prior to the COVID-19 pandemic

\begin{tabular}{llllllll}
\hline & $M$ & $S D$ & 1 & 2 & 3 & 4 \\
\hline 1 & Work-Related Email Use After Hours & 3.36 & 1.46 & $(.97)$ & & & \\
2 & Psychological Detachment & 3.03 & 0.98 & $-.63^{*}$ & $(.88)$ & & \\
3 & Work-Family Conflict & 2.49 & 0.97 & .02 & $-.24^{*}$ & $(.89)$ \\
4 & Emotional Exhaustion & 3.93 & 1.70 & -.04 & -.12 & $.48^{*}$ & $(.90)$ \\
\hline
\end{tabular}

Note. ${ }^{*} \mathrm{p}<.05$; Cronbach's alpha presented along diagonal 


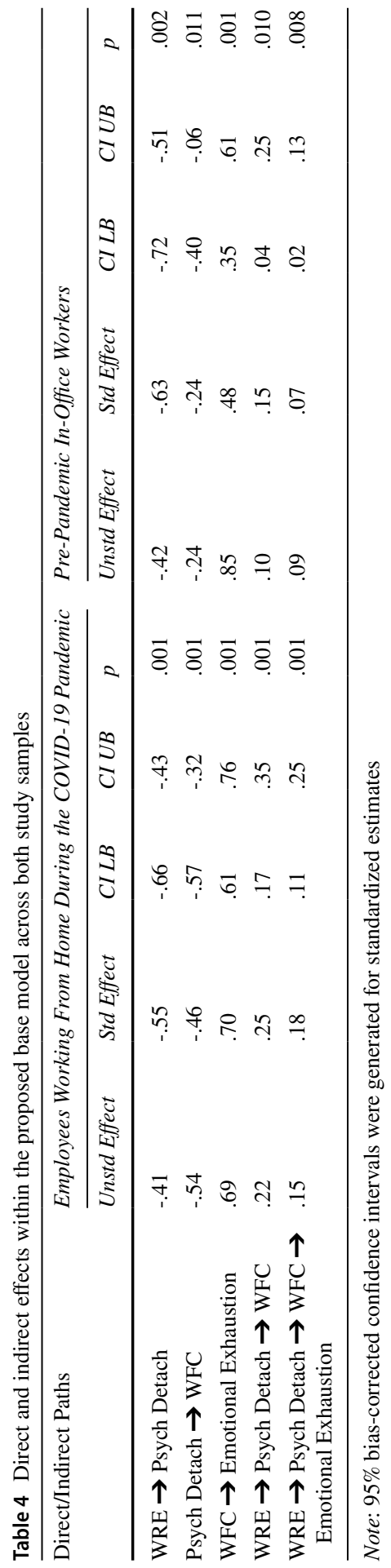


paths, except from WRE use to psychological detachment, were greater in the WFH sample. The direct effect from WRE use to psychological detachment was stronger in the in-office worker sample. Therefore, $\mathrm{H} 7$ was partially supported.

\section{Discussion}

This study contributes to our knowledge of relationships between work-related technology and employee wellbeing during the COVID-19 pandemic by examining the mechanism through which WRE use during nonwork hours may relate to emotional exhaustion in workers required to WFH. In line with the stressor-detachment model (Sonnentag \& Fritz, 2015) and boundary theory (Ashforth et al., 2000), results from this study suggest that psychological detachment and WFC play key roles in WRE use's relationship with wellbeing. In addition, the relationship between WRE use and psychological detachment intensifies for those who tend to be preoccupied with and/or have the urge to respond to messages when they receive them (i.e., those high in telepressure). In essence, keeping up with WRE during nonwork hours may encourage employees to maintain an "always on" mentality, and may take up mental real estate during nonwork time, not allowing them to properly disconnect from the workplace. When employees are not able to sufficiently detach from work while "off the clock," they may experience conflict between the work and family/home domains, and in turn, become emotionally exhausted.

The second aim of this study was to examine whether after hour WRE use's relationships with WFC and wellbeing would hold outside of the COVID-19 context. To meet this aim, a path model was fit to data collected from a sample of administrative assistants during the COVID-19 pandemic, and that same model was tested using data collected from an independent sample of administrative assistants, working inoffice, collected prior to COVID-19. The model showed good fit to data from both samples, and all direct and indirect effects were significant across both samples, suggesting that the indirect effect of WRE use during nonwork hours on emotional exhaustion holds for both in-office workers and those required to WFH. However, most effects were found to be stronger in employees required to WFH. This may be because for employees who WFH, lacking the physical separation of work and home environments may result in a more permeable boundary between the two domains, which could be associated with increased conflict and have negative implications on wellbeing.

Interestingly, the effect of WRE use during nonwork hours on psychological detachment was found to be stronger for in-office workers than for those required to WFH. This finding may suggest that those with physically separate home and work environments may create more concrete boundaries between the two domains, and if this boundary is penetrated by work demands (e.g., through checking WRE during nonwork hours), there may be more difficulty psychologically detaching from work. For workers required to WFH during the pandemic, the work-home boundary may be more permeable, making the mental transition from work and family roles a little more fluid (Ashforth et al., 2000). One reason for this may be because the changes to the work environment are shared 
experiences with others in similar situations, as well as other household members. Although those working from home during the COVID-19 pandemic may experience a slight protection of their psychological detachment from increased WRE use during nonwork hours, the overall indirect effects of WRE use during nonwork hours on WFC and emotional exhaustion were stronger for WFH workers than in-office workers. These differences in effects found across the two study samples offer novel insights into how shifting to a WFH environment may exacerbate the negative effects of WRE use after hours on worker wellbeing. Further, these findings make an important contribution to the literature by identifying which linkages may be intensified when workers face dramatic changes to how and where work is conducted. This knowledge allows employers to be better prepared to meet employee needs and protect worker health if major disruptions to how we work are encountered again in the future.

\section{Practical Implications}

This study yields several practical implications for both employees and employers. First, keeping up with WRE during nonwork was found to have negative implications for work/family balance and wellbeing for both in-office workers and those required to WFH. Therefore, employees wishing to protect their nonwork time to psychologically detach from the workday may wish to create a concrete boundary between their work and home domains, and refrain from checking their WRE during nonwork hours. Those who wish to keep up with WRE during nonwork hours, or those who experience high telepressure, may benefit from setting aside times to check WRE after work hours rather than checking emails as they are received. This may allow for longer periods of psychological detachment and may offer some protection against WFC and emotional exhaustion.

Organizational leadership should consider the impact of WRE sent during nonwork hours on employee wellbeing, as organizational expectations to monitor WRE during nonwork hours can have negative implications for employee work/ home and wellbeing outcomes (Becker et al., 2018; Belkin et al., 2020). It is particularly important for managers to keep in mind that for those required to WFH, the lack of physical separation between the work and home environment may amplify the negative implications of WRE use after hours. Therefore, managers should encourage transparency of preferences and respectful email practices, especially in the WFH context. For example, for workplaces with a structured workday (e.g., business hours from 9 AM to 5 PM), managers could encourage the practice of sending WRE during business hours only or delaying the delivery of an email if it is drafted outside of business hours. Alternatively, if the workplace does not have a structured workday, managers should encourage employees to be transparent about their work hours (or conversely, the times that they are not available) and should strive to create a work environment in which employees' availabilities are acknowledged and respected. 
Leaders should also consider that individuals can differ in their tendencies to check and respond to WRE during nonwork hours. Although reading or responding to WRE while "off the clock" may not be mandatory, those high in telepressure may feel a sense of urgency in checking or replying to messages as they arrive. In an effort to protect workers' wellbeing and workfamily balance, management may wish to regulate the use of WRE during nonwork hours and encourage employees to send emails only during business hours (or schedule to send emails during business hours). This is especially important for workers required to WFH, where the effects of WRE during nonwork hours were found to have greater adverse relationships with WFC and emotional exhaustion.

\section{Limitations and Future Directions}

Although this study yields several important findings, it should be noted that cross-sectional data were collected in this study, which only allows for the examination of noncausal effects. However, given the sudden shift to working from home and increased reliance on technology due to the COVID-19 pandemic, there is an immediate need for empirical investigation into how technology and the WFH environment relate to employee health and wellbeing. Therefore, the use of cross-sectional data may be justified given that the purpose of this study was to investigate relationships between WRE email use during nonwork hours and work/family and wellbeing outcomes in a novel sample (i.e., employees required to WFH) and in a unique context (i.e., during a global pandemic). Further, several alternative path models were tested to investigate whether alternate mechanisms may better explain the relationships among the study variables. Results of these tests showed that the original study models had superior fit to the data than the alternatives tested, which provides support for the pathways proposed in this study and the interpretation of findings. Although cross-sectional data could be appropriate for initial stages of research during this time, these relationships should be further evaluated and confirmed using alternative research designs such as experimental or longitudinal to confirm the directionality of the relationships proposed in the present research. Future research should also aim to investigate alternative mechanisms and conditions under which these phenomena occur. For example, experiences of emotional exhaustion could impact the degree to which one keeps up with their WRE after hours, and this relationship may look different for those who experience telepressure, are highly engaged in their work, and/or have difficulties with self-regulation.

Second, single-source (self-report) data were collected in both samples, making common method bias a possible limitation (Podsakoff et al., 2003). However, subjective measures are likely to be most appropriate for most study variables (i.e., psychological detachment, telepressure, WFC, emotional exhaustion) due to the subjective nature of the phenomena. Future research could use more objective measures for assessing variables such as WRE use after hours. For example, 
the numbers of emails sent, received, and checked by employees after work hours could be tracked and tallied, which may be a more objective method of measuring the degree to which employees keep up with their WRE after hours. The amount of time that employees spend keeping up with their WRE after hours could also serve as an indicator of the degree to which they engage in this behavior. Further, selfreport data could be supplemented with data collected from other members of the household to measure WFC.

Third, the differences in demographic characteristics of the two samples studied should be noted as a limitation when making comparisons across samples. Specifically, significant differences were found in age, hours worked per week, salary, job tenure, and organizational tenure. Generally, the WFH sample consisted of individuals who were, on average, older, worked more hours per week, had a higher salary, and had been working in their current job and organization for longer. Future research should investigate how factors such as tenure, salary, and hours worked can impact an individual's tendency to keep up with their WRE after hours, ability to psychologically detach from work, and experiences of WFC and exhaustion.

Future research should also examine whether keeping up with WRE during nonwork hours is impacted by the content of the email, and/or the frequency at which email is checked during nonwork hours. Additional job-related and wellbeing outcomes of WRE use during nonwork hours, such as job performance, engagement, job satisfaction, life satisfaction, and physical health, should also be explored. Finally, future research should investigate additional moderators of the relationships proposed. Personality and individual differences, such as conscientiousness or segmentation preference, and organizational factors, such as workplace norms and supervisor support, are likely to play moderating roles within the model.

\section{Conclusion}

The COVID-19 pandemic has greatly impacted how, where, and when work is done. This sudden shift to working from home and sharp increase in our reliance on workrelated technology calls for immediate investigation into how these factors relate to employee work/family balance and wellbeing. This study sheds light onto the work/ family and wellbeing implications of WRE use during nonwork hours in employees who are working from home due to the COVID-19 pandemic and further suggests that these relationships are likely to hold, albeit less intensively, outside of the pandemic context. Findings from this study can be used as foundation for future research, and lawmakers, organizations, employees, and practitioners should consider the implications of WRE use outside of work hours on employees' health and wellbeing when crafting laws, policies, and organizational strategies.

\section{Declarations}

Conflicts of interest/Competing interests There are no known conflicts of interest to disclose.

Availability of data and material Data available upon request. 


\section{References}

Adobe (2019). Email usage - Working age knowledge workers (US trended results). https://www.slide share.net/adobe/2019-adobe-email-usage-study

Allen, T. D., Herst, D. E. L., Bruck, C. S., \& Sutton, M. (2000). Consequences associated with workto-family conflict: A review and agenda for future research. Journal of Occupational Health Psychology, 5(2), 278-308. https://doi.org/10.1037/1076-899B.5.2.278

American Psychological Association (2006). Multitasking: Switching costs. https://www.apa.org/ research/action/multitask

Ashforth, B. E., Kreiner, G. E., \& Fugate, M. (2000). All in a day's work: Boundaries and micro role transitions. Academy of Management Review, 25(3), 472-491. https://doi.org/10.5465/amr.2000. 3363315

Baranzini, D. (2018). The BAR procedure. https://doi.org/10.13140/RG.2.2.33750.70722

Barber, L. K., \& Jenkins, J. S. (2014). Creating technological boundaries to protect bedtime: Examining work-home boundary management, psychological detachment and sleep. Stress and Health, 30, 259-264. https://doi.org/10.1002/smi.2536

Barber, L. K., \& Santuzzi, A. M. (2015). Please respond ASAP: Workplace telepressure and employee recovery. Journal of Occupational Health Psychology, 20(2), 172-189. https://psycnet.apa.org/ doi/https://doi.org/10.1037/a0038278

Becker, W. J., Belkin, L., \& Tuskey, S. (2018). Killing me softly: Electronic communications monitoring and employee and spouse well-being. Academy of Management Proceedings, 2018(1). https://doi.org/10.5465/AMBPP.2018.121

Behrend, T. S., Sharek, D. J., Meade, A. W., \& Wiebe, E. N. (2011). The viability of crowdsourcing for survey research. Behavior Research Methods, 43(3), 800-813. https://doi.org/10.3758/ s13428-011-0081-0

Belkin, L. Y., Becker, W. J., \& Conroy, S. A. (2020). The invisible leash: The impact of organizational expectations for email monitoring after-hours on employee resources, well-being, and turnover intentions. Group \& Organization Management, 45(5), 709-740. https://doi.org/10.1177/2F105 9601120933143

Boswell, W. R., \& Olson-Buchanan, J. B. (2007). The use of communication technologies after hours: The role of work attitudes and work-life conflict. Journal of Management, 33(4), 592-610. https://doi.org/10.1177/2F0149206307302552

Clark, S. C. (2002). Communicating across the work/home border. Community, Work \& Family, 5(1), 23-48. https://doi.org/10.1080/13668800020006802

Demsky, C. A., Ellis, A. M., \& Fritz, C. (2014). Shrugging it off: Does psychological detachment from work mediate the relationship between workplace aggression and work-family conflict? Journal of Occupational Health Psychology, 19(2), 195-205. https://psycnet.apa.org/doi/https://doi.org/ $10.1037 / \mathrm{a} 0035448$

Derks, D., van Mierlo, H., \& Schmitz, E. B. (2014). A diary study on work-related smartphone use, psychological detachment and exhaustion: Examining the role of the perceived segmentation norm. Journal of Occupational Health Psychology, 19, 74-84. https://psycnet.apa.org/ doi/https://doi.org/10.1037/a0035076

Dettmers, J. (2017). How extended work availability affects well-being: The mediating roles of psychological detachment and work-family-conflict. Work \& Stress, 31(1), 24-41. https://doi.org/10. 1080/02678373.2017.1298164

Etzion, D., Eden, D., \& Lapidot, Y. (1998). Relief from job stressors and burnout: Reserve service as a respite. Journal of Applied Psychology, 83(4), 577-585. https://psycnet.apa.org/doi/https://doi. org/10.1037/0021-9010.83.4.577

Fluent (2018). The inbox report: Consumer perceptions of email. https://www.fluentco.com/reports/ the-inbox-report/

Germeys, L., \& De Gieter, S. (2017). Psychological detachment mediating the daily relationship between workload and marital satisfaction. Frontiers in Psychology, 7, 2036. https://doi.org/10. 3389/fpsyg.2016.02036

Golden, A. G. (2013). The structuration of information and communication technologies and worklife interrelationships: Shared organizational and family rules and resources and implications for work in a high-technology organization. Communication Monographs, 80(1), 101-123. https:// doi.org/10.1080/03637751.2012.739702 
Hu, X., Park, Y., Day, A., \& Barber, L. K. (2021). Time to disentangle the information and communication technology (ICT) constructs: Developing a taxonomy around ICT use for occupational health research. Occupational Health Science, 5, 217-245. https://doi.org/10.1007/s41542-021-00085-6

Kao, K. Y., Chi, N. W., Thomas, C. L., Lee, H. T., \& Wang, Y. F. (2020). Linking ICT availability demands to burnout and work-family conflict: The roles of workplace telepressure and dispositional self-regulation. The Journal of Psychology, 154(5), 325-345. https://doi.org/10.1080/00223980. 2020.1745137

Lerman, R. \& Greene, J. (2020). Big Tech was first to send workers home. Now it's in no rush to bring them back. https://www.washingtonpost.com/technology/2020/05/18/faceb ook-google-work-from-home/

Makarius, E. E., Larson, B. Z., \& Vroman, S. R. (2021, March 24). What is your organization's long-term remote work strategy? Harvard Business Review. https://hbr.org/2021/03/what-is-your-organizati ons-long-term-remote-work-strategy

Manapragada, A. (2017). The "always on" employee: The antecedents and consequences of work-related email use after hours [Doctoral dissertation, Florida International University]. https://doi.org/10. 25148/etd.FIDC001945

Maslach, C., Schaufeli, W. B., \& Leiter, M. P. (2001). Job burnout. Annual Review of Psychology, 52(1), 397-422. https://doi.org/10.1146/annurev.psych.52.1.397

Medrano, L. A., \& Trógolo, M. A. (2018). Employee well-being and life satisfaction in Argentina: The contribution of psychological detachment from work. Journal of Work and Organizational Psychology., 34(2), 69-81. https://doi.org/10.5093/jwop2018a9

Minnen, M. E., Mitropoulos, T., Rosenblatt, A. K., \& Calderwood, C. (2020). The incessant inbox: Evaluating the relevance of after-hours e-mail characteristics for work-related rumination and wellbeing. Stress and Health, 1-12https://doi.org/10.1002/smi.2999

Molino, M., Cortese, C. G., Bakker, A. B., \& Ghislieri, C. (2015). Do recovery experiences moderate the relationship between workload and work-family conflict? Career Development International, 20(7), 686-702. https://doi.org/10.1108/CDI-01-2015-0011

Moreno-Jiménez, B., Mayo, M., Sanz-Vergel, A. I., Geurts, S., Rodríguez-Muñoz, A., \& Garrosa, E. (2009). Effects of work-family conflict on employees' well-being: The moderating role of recovery strategies. Journal of Occupational Health Psychology, 14(4), 427-440. https://psycnet.apa.org/ doi/https://doi.org/10.1037/a0016739

Netemeyer, R. G., Boles, J. S., \& McMurrian, R. (1996). Development and validation of work-family conflict and family-work conflict scales. Journal of Applied Psychology, 81(4), 400-410. https:// psycnet.apa.org/doi/https://doi.org/10.1037/0021-9010.81.4.400

Park, Y., Fritz, C., \& Jex, S. M. (2011). Relationships between work-home segmentation and psychological detachment from work: The role of communication technology use at home. Journal of Occupational Health Psychology, 16(4), 457-467. https://doi.org/10.1037/a0023594

Plummer, M. (2019). How to spend way less time on email every day. Harvard Business Review. https:// hbr.org/2019/01/how-to-spend-way-less-time-on-email-every-day

Podsakoff, P. M., MacKenzie, S. B., Lee, J., \& Podsakoff, N. P. (2003). Common method biases in behavioral research: A critical review of the literature and recommended remedies. Journal of Applied Psychology, 88(5), 879-903. https://psycnet.apa.org/doi/https://doi.org/10.1037/0021-9010.88.5. 879

PoliteMail (2020). COVID-19's lasting impact on corporate communications. https://politemail.com/ resource-center/whitepapers-for-internal-communications/what-the-covid-happened-to-internalcommunications/

The Radicati Group (2019). Email Statistics Report, 2019-2023. Retrieved from https://www.radicati. com/wp/wp-content/uploads/2018/12/Email-Statistics-Report-2019-2023-Executive-Summary.pdf

Santuzzi, A. M., \& Barber, L. K. (2018). Workplace telepressure and worker well-being: The intervening role of psychological detachment. Occupational Health Science, 2, 337-363. https://doi.org/10. 1007/S41542-018-0022-8

Schaufeli, W. B., Leiter, M. P., Maslach, C., \& Jackson, S. E. (1996). The Maslach Burnout Inventory General Survey. In C. Maslach, S. E. Jackson, \& M. P. Leiter (Ed.), MBI manual (3rd ed.). Consulting Psychologists Press.

Sonnentag, S. (2012). Psychological detachment from work during leisure time: The benefits of mentally disengaging from work. Current Directions in Psychological Science, 21(2), 114-118. https://doi. org/10.1177/2F0963721411434979 
Sonnentag, S., \& Bayer, U. V. (2005). Switching off mentally: Predictors and consequences of psychological detachment from work during off-job time. Journal of Occupational Health Psychology, 10(4), 393-414. https://psycnet.apa.org/doi/https://doi.org/10.1037/1076-8998.10.4.393

Sonnentag, S., Binnewies, C., \& Mojza, E. J. (2008). "Did you have a nice evening?" A day-level study on recovery experiences, sleep, and affect. Journal of Applied Psychology, 93(3), 674-684. https:// doi.org/10.1037/0021-9010.93.3.674

Sonnentag, S., \& Fritz, C. (2007). The Recovery Experience Questionnaire: Development and validation of a measure for assessing recuperation and unwinding from work. Journal of Occupational Health Psychology, 12(3), 204-221. https://psycnet.apa.org/doi/https://doi.org/10.1037/1076-8998. 12.3.204

Sonnentag, S., \& Fritz, C. (2015). Recovery from job stress: The stressor-detachment model as an integrative framework. Journal of Organizational Behavior, 36(S1), S72-S103. https://doi.org/10.1002/ job. 1924

Sonnentag, S., Kuttler, I., \& Fritz, C. (2010). Job stressors, emotional exhaustion, and need for recovery: A multi-source study on the benefits of psychological detachment. Journal of Vocational Behavior, 76(3), 355-365. https://psycnet.apa.org/doi/https://doi.org/10.1016/j.jvb.2009.06.005

Towers, I., Duxbury, L., Higgins, C., \& Thomas, J. (2006). Time thieves and space invaders: Technology, work and the organization. Journal of Organizational Change Management, 19(5), 593-618. https:// psycnet.apa.org/doi/https://doi.org/10.1108/09534810610686076

U.S. Bureau of Labor Statistics (2020). Ability to work from home: Evidence from two surveys and implications for the labor market in the COVID-19 pandemic. Monthly Labor Review. https://www. bls.gov/opub/mlr/2020/article/ability-to-work-from-home.htm

van Laethem, M., van Vianen, A. E. M., \& Derks, D. (2018). Daily fluctuations in smartphone use, psychological detachment, and work engagement: The role of workplace telepressure. Frontiers in Psychology, 9, 1808. https://doi.org/10.3389/fpsyg.2018.01808

van Veldhoven, M. J. P. M. (2008). Need for recovery after work: An overview of construct, measurement and research. In J. Houdmont \& S. Leka (Eds.), Occupational health psychology: European perspectives on research, education and practice (pp. 1-25). Nottingham University Press.

Publisher's Note Springer Nature remains neutral with regard to jurisdictional claims in published maps and institutional affiliations. 